\title{
Moral Demands of Outdoor Sports in China from the Perspective of Ethics
}

\author{
Gu Xufeng \\ School of Physical Education of Changzhou University, Changzhou, Jiangsu, China, 213164
}

Keywords: Ethics; Outdoor sports; Moral; Demands; Perspective of ethics

\begin{abstract}
This paper has researched a variety of moral issues arising in the development course of outdoor sports in our country by the method of literature and the empirical analysis from the perspective of ethics. The results of the study show that the moral issues in the development of outdoor sports in China are sorted into three aspects, including individual participants, group participants and organizers. The paper has further analyzed the moral demands of these three groups and provided a reference for the harmonious development of outdoor sports in China
\end{abstract}

\section{Introduction}

The outdoor sports can not develop without people. People are the precondition to develop the outdoor sports. The paper has discussed the moral demands from three angles, covering the individual participants, group participants and organizers, in order to provide a theoretical basis for the healthy and harmonious development of the outdoor sports in our country.

\section{The Moral Demands of Individual Participants}

In outdoor sports, individual participants have the obvious characteristic of independence. They mainly pursue physical health, personality shaping, freedom spirit and closeness to nature, which highlights moral demands through the pursuit of individual physical and mental health, goodness in human nature and freedom spirit.

The Pursuit of Physical and Mental Health and Harmony and Unity. Individuals can participate in specific outdoor activities, because it can stimulate the biopotency of the body and produce benign reaction to people's recognition. In the gradual change process, the individual participants could reach a state with a healthy and harmonious mind and body. In other words, the individuals' cognition, emotion, will and behavior are complete and coordinated in order to adapt to the outdoor sports. In this way, the participants can keep harmonious with outdoor sports. In outdoor sports, individual participants pursue the health, harmony and unity of body and mind, which can make our body and temperament healthy, stable, happy and satisfied through the internal mechanism of the outdoor activities[1]. It is an important symbol of the body and mind to be harmonious, united and healthy. It is an coordination and unification of will and behavior starting from selecting favorite outdoor sports, to planning to arrange favorable route, time and equipment, until to participating in and finishing activities happily. Only by coordinating and unifying our thought and behavior, with the ability of self-control, can we achieve the state with a harmonious and untied body and mind. In the process of activities, we could know ourselves comprehensively and rationally, not misinterpret our characters, nor zoom our strengths and weaknesses. We understand what we are doing and what we are pursuing[2].

The Pursuit of Goodness in Human Nature. "Goodness" in the Chinese language means auspiciousness, happiness and virtue. It is to pursue the value of goodness for individuals to participate in outdoor sports. On one hand, it reflects the pursuit of healthy and good relationship between people and nature for individual participants to comply with the ethical principles and norms of outdoor sports. 
On the other hand, it is an important prerequisite to maintain a harmonious relationship, improve own personality and be a moral person. It is an internal logic to pursue the goodness in human nature. The pursuit of goodness in human nature is to shape a sound personality. Individuals can form a positive personality through participating and finishing outdoor sports and then possess objective self-cognition and attitude, social consciousness and enthusiasm of life philosophy. The outdoor sports can help individuals establish good interpersonal relationship and ability to solve problem effectively, and finally make individual personality structure coordinated. As main body of outdoor sports, the participants should know ourselves objectively and possess positive self attitude. The pursuit of goodness in human nature could help people love outdoor sports, adjust their personality structure and possess unified values for outdoor sports and make their belief, motivation and action harmonious[3].

The Pursuit of the Freedom Spirit. The pursuit of independence is a concrete manifestation of the individual to participate in outdoor sports and thus obtain the freedom spirit. The individuals are the main body of outdoor sports. In the development of outdoor sports, the development degree of awareness marks the development level of independence and consciousness, which is a premise for individual to pursue the freedom spirit. It is not a physiological instinct for individuals to select, participate and finish outdoor sports, but a desire to stand on their own. For a long time, people shuttle back and forth in reinforced concrete city, and we have forgotten the sense of freedom that the nature gives us. Instead of this, we are constrained by complex and changeable social rules. We do not oppose the constraint effect, but we should not ignore the freedom spirit in human nature, especially the individual independence from the freedom spirit. To go on a walk in mountains and rivers, we would be attracted by the beauty of nature whether we experience and enjoy the beauty of nature consciously or unconsciously. If there is no freedom spirit, we would not pursue the individual independence. Then, it makes little sense to for people to participate in outdoor sports. People's life would become boring, just like animal's. We may only succumb to the physiological needs, like a slave with no happiness.

\section{The Moral Demands of Group Participants}

The group participant refers to a group with two or more teammates to participate in outdoor sports, which requires every member to use their knowledge and skills to carry out outdoor sports. The member participating in activities should possess a strong sense of collective spirit, such as solidarity, cooperation, mutual benefit, integrity and goodness and other good concepts and values.

The Pursuit of Unity and Friendship in Groups. The reason for the rise of outdoor sports: on the one hand, people lack "team spirit" in real work and life. The apathy of real social relations and the boredom and resistance to these relations make people eager to return to unrestricted social space and vent feelings. On the other hand, people want to feel the great power in the group through challenging life limit and mining the mystery of life. Whether a group participating in outdoor sports possesses collective spirit or the group has a same goal and pursuit depends on the group's ethical pursuit for unity. In a united group, all members form a strong harmonious atmosphere. Members could get along with each other happily and care for each other and progress together and overcome difficulties and thus achieve the goal. In participation of the outdoor sports, it is difficult to give mature consideration to all aspects, especially for the novice or new members. They may lack experience in the start of participation in outdoor activities, as well as equipment and skills and have mental defects. The equipment and skills can be obtained through short-time training[4], but the sense of fear and doubt is difficult to eliminate, which requires friendship and mutual help among members. It is the best way to solve these problems by giving a hand to support members in the group, for it is a great comfort to the members. It also has obvious help for the group participants in outdoor sports.

The Pursuit of Mutual Benefit and Cooperation in Groups. The biggest characteristic of the group participating in outdoor sports is that they must rely on collective strength to complete the target successfully. Members can not only rely on themselves to carry out activities. They should cooperate 
with each other, overcome setbacks and difficulties together. Only the success of the group has significance and value. The significance and value are the requirement of intrinsic value of outdoor sports, and the internal logic to reflect the value of individual participating in outdoor sports. The internal requirements and demands reflected through the concept of mutual benefit and cooperation also will be the positive force for the development of outdoor sports and individual. In the process of outdoor sports, it will inevitably encounter some safety emergencies, such as diarrhea, dislocation, dehydration, drowning, fainting, shortness of breath, food poisoning, vomiting and so on. At this time, personal power will be very weak. Though one can overcome the immediate difficulties, it is difficult to continue to complete activities. This moment it is particularly important for the teammates to help him or her. The teammates can help the wounded carry heavy equipment and go forward or stay with the wounded to wait for the rescue team. It seams like a small matter, but bring a great comfort to the member's body and mind. It is also an effective way to avoid trouble and help the group continue the activity[5].

The Common Pursuit of Integrity and Goodness in Groups. The mutual cooperation among members relies on direct and indirect help between each other. It is very easy to be destroyed. The integrity and goodness is the powerful tool to solve this problem. In outdoor groups, members can know each other through a series of behaviors and conversations, and thus trust each other and collect wisdom to overcome difficulties. It can be seen that the common pursuit of integrity and goodness in groups is the core belt to maintain the friendship and mutual benefit and cooperation of the group members in outdoor activities. At same time, unity and cooperation have become a kind of mutual understanding and performance between group members. All mentality, concepts and behaviors manifest the group's pursuit for goodness. In the course of the activity, with goodness as moral basis, the individuals internalize "should" and "shouldn't" into moral concepts and behaviors, which can reflect the understanding, tolerance, justice, support, help, modest quality, and achieve unity and friendship, cooperation and mutual benefit. Although the goodness can not fully guarantee the harmonious development of outdoor groups, but it can provide positive energy to the group.

\section{The Moral Demands of the Outdoor Sports Organizers}

Outdoor sports organizers are the core personnel to launch, organize and manage outdoor sports, which include organizers of "tour pal" spontaneous activities, dutch treatment activities, profit club and enterprise activities. It can be divided into different organizer body from the view of economics, but the responsibilities and tasks of each organizer body are consistent, with same ethic appeal. It has the ethic requirements of democratization and humanitarian in the activity organization, management and participation[6].

The Pursuit of People Orientation. It is core value of people-oriented ethic spirit for organizers to stress the dominant role of outdoor sports participants. The outdoor sports organizers have a variety of authorities to organize, plan and manage the route and schedule and other matters of outdoor sports. Outdoor sports participants carry out the contents of activities under the guidance, and they can not act without organizers. However, organizers can not replace the special status of participants in the outdoor sports. In other words, participants, as basic "cells" are the decisive factor in the operation of activity. In the activity, there is a detailed plan, tacit teamwork and complete equipment, however, it needs real people to operate and use. If organizers break away from the participants to carry out outdoor sports, it will deviate from the original intention of outdoor sports. The core target of these activities for participants is the individual experience, so participants are always the support force and cohesive force. In outdoor sports, the ability level and the experience of individual and the complete level of equipment are different, so that the experience of individual is also different. There are significant differences. At the same time, many details in activities require individual to sacrifice for 
others. Therefore, it is particularly important for organizers to ensure every member is able to defuse crisis and contradiction, enjoy the happiness in the outdoor sports comprehensively and reasonably.

The Pursuit of Responsibility and Service. The leadership responsibility of outdoor sports organizers is to make strategy, implement correct concept and correct behavior, reflecting in the maintenance of collective and individual interests and making all internal elements of group toward the development direction of "goodness". All members should listen to organizer, so the authority is given to the organizer virtually. The organizer shall ensure every member are safe and be able to finish the activities happily and smoothly. The concept of service is a distinctive feature in the business development of modern outdoor sports. In outdoor sports, the organization managers have transformed their role from passively receiving tasks into actively providing knowledge, technology and other resources, thus achieve the collective value in continuous personalized creation. It makes the organizers re-position management nature of outdoor sports and take service concept into organization and management. "Consumer awareness" has come very naturally into the outdoor sports area. Emphasis on "customer consciousness" will force organizers to focus on every participant in outdoor sports. The management, planning and implementation of the outdoor sports are all focused on participants[7].

The Pursuit of Selflessness and Nature. It is a common problem to be "egoistic" in the management and organization process of outdoor sports. All participants should listen to the organizer and follow the organizer's decision, for almost all things are decided by the organizer. However, personal judgment will become narrow involuntarily due to personal preferences and experience influence, for it tends to meet personal interest and enjoyment. Therefore, it is difficult to meet the requirements of other members and it needs someone to be selfless and sacrifice themselves. The people orientation needs "selflessness", "self-sacrifice oneself" and "overall situation". It is an inner presentation to understand the value of people correctly. As the management authority, the organizers shall give full play to their positivity and initiative, thus create a total-member management mode and break the traditional mode of "exclusive right". Let every member participate in management. It can maintain the nature to be "selfless" and "democratic". To be "nature" is the value of outdoor sports, the "liberation" of body and mind that individual participants pursue in the outdoor sports, and the interpretation of the value of "goodness" in the group. Organizers should take responsibility, be with less selfishness and more collectivity, less desire and more rationality, treat individual as the main body of group development, in order to truly reflect the value and significance of outdoor sports[8].

\section{Conclusion}

As an important part of the national fitness, the safe and harmonious outdoor sports are aimed to improve people's physical and mental health[9], enrich our life, create pleasure and perfect ourselves. People can do some physical and psychological exercise through participating in some activities organized by government-recognized or social recognized organizations. The individuals and groups can get the natural harmony and healthy development of body, mind, interpersonal relationships, between human and society[10], man and nature. Through humane and democratic management, organizers could bear the responsibility to maintain the friendship and mutual benefit among teammates, and the united and progressive atmosphere, virtually forming a specific ethic demand. The paper has researched the moral demands in the development of our outdoor sports from the angle of ethics in order to provide some theoretical reference for the healthy and harmonious development of the outdoor sports in our country. 


\section{References}

[1] The Guidance Center of National Vocational Skill Appraisal of State General Administration of Sports. Social sports instructor training materials (primary) [M]. Beijing: Higher Education Press, 2012:19 - 26.

[2] Chinese Lifesaving Association of Guidance Center of National Vocational Skill Appraisal of State General Administration of Sports. Swimming lifeguard rescue (swimming pool) [M]. Beijing: Higher Education Press, 2012:126-127.

[3] State General Administration of Sports. Management measures for operating high-risk sports license [Z]. State General Administration of Sports [2013] No.17, 2013, 5-1 2013.

[4] State General Administration of Sports. High risk sports (swimming) conditions and procedures for examination and approval [Z]. State General Administration of Sports [2013] No. 17, 2013, 5-1 2013.

[5] Starting a Club.[EB/OL].[2014-03-08]. http://www.usaswimming.org/DesktopDefault.aspx?TabId=1606\&Alias=Rainbow\&Lang=en.

[6] Fang Qianhua, Mei Xuexiong. Comparative study of domestic and foreign public swimming lifeguard training system [J]. Journal of Capital Institute of Physical Education, 2008, 20 (3) : 41-44.

[7] Chinese Lifesaving Association. Swimming lifeguard [M]. Beijing: Higher Education Press, 2010:4-5.

[8] Fang Qianhua, Mei Xuexiong. The development and enlightenment of the foreign lifesaving[J]. Journal of Sports Science Research, 2005, 9 (1) : 21-25.

[9] The lifeguard training schedule. [EB/OL].http://www.sdtyrc.gov.cn/news1.aspx?id=92.

[10] Lifeguard certification and recertification schedule.[EB/OL]. http://vancouver.ca/your-government/lifeguard-training.aspx. 